\title{
Interaction of Recruiter and Applicant Gender in Resume Evaluation: A Field Study
}

\author{
Michael S. Cole, ${ }^{1,3}$ Hubert S. Feild, ${ }^{2}$ and William F. Giles ${ }^{2}$
}

\begin{abstract}
In the present study, we examined the effect of recruiter and applicant gender on recruiters' evaluations of applicants' qualifications as reported on actual applicant resumes. Forty recruiters evaluated applicant resumes that were randomly allocated to them. In total, 388 recruiter evaluations of applicant resumes comprised the sample. Results indicate that recruiter and applicant gender interacted to predict recruiters' perceptions of applicants' qualifications. Male recruiters' perceptions of applicants' work experiences did not differ depending on applicant gender. However, female recruiters perceived male applicants' resumes to report more work experiences than resumes of female applicants. Furthermore, male recruiters perceived female applicants as having more extracurricular interests than male applicants. Female recruiters rated both male and female applicants as having about the same amount of extracurricular activity information on their resumes. Gender role theory provides a possible explanation for the study's findings.
\end{abstract}

KEY WORDS: resumes; preemployment; recruiter; gender differences.

More than 25 years ago, it was estimated that one billion resumes and applications were screened each year (Levine \& Flory, 1975), and that number has certainly risen. For example, it is not atypical for an organization to review more than 50,000 resumes in a year's time (Useem, 1999). With the advent of resume submission via the internet (Lievens, van Dam, \& Anderson, 2002; Mohamed, Orife, \& Wibowo, 2002), evaluation of applicants' resumes is likely to continue as an important preemployment screening device.

Employers use resumes as an initial applicant screening tool because they provide an opportunity to appraise applicants' qualifications in areas such asx education, work experience, and special skills

\footnotetext{
${ }^{1}$ Institute for Leadership and Human Resource Management, University of St. Gallen, Switzerland.

${ }^{2}$ Department of Management, Auburn University, Auburn, Alabama.

${ }^{3}$ To whom correspondence should be addressed at Institute for Leadership and Human Resource Management, Dufourstrasse 40a, CH-9000 St. Gallen, Switzerland; e-mail: Michael.Cole@unisg.ch.
}

(Knouse, 1989). Because employers can make these initial assessments prior to investing in more expensive selection measures such as interviews, reviewing applicants' resumes is a common practice when filling entry-level positions (Hutchinson, 1984), especially for those organizations that consider large numbers of applicants for a limited number of job openings (Gatewood \& Feild, 2001).

Resumes establish recruiters' first impressions of applicants' employability, and these impressions, in turn, are used to make prehire decisions (Ash, Johnson, Levine, \& McDaniel, 1989; Dipboye, Fontenelle, \& Garner, 1984; Hakel \& Schuh, 1971). Unfortunately, the manner in which recruiters process applicant information is often informal, unstructured, and may vary among individual evaluators (Ash et al., 1989; Graves, 1993). Moreover, past research has demonstrated decision biases (Cable \& Gilovich, 1998; Dougherty, Turban, \& Callender, 1994) and idiosyncratic patterns in how recruiters process and use informational cues (Bretz, Rynes, \& Gerhart, 1993; Kinicki, Lockwood, Hom, \& Griffeth, 1990; Zedeck, Tziner, \& Middlestadt, 1983). 
When recruiters' perceptual biases have the potential to make a negative impact on legally protected groups (e.g., women), these biases may place the organization at legal risk and deprive the organization of valuable sources of talent. In relation to such biases, female applicants have been the subject of research on the resume screening process. However, this research, much of which was conducted over 25 years ago, generally used fictitious resumes and had students serve as judges in laboratory settings (e.g., Cohen \& Bunker, 1975; Dipboye, Arvey, \& Terpstra, 1977; Dipboye, Fromkin, \& Wiback, 1975). In contrast to this body of simulated resume rating research, the primary purpose of the present study was to determine if experienced recruiters would exhibit gender-linked perceptual biases when evaluating actual job applicants' resumes. Such a study is important because the results of resume screening often determine which applicants receive subsequent invitations for further assessments. Before we present specific hypotheses, we discuss a particular perceptual bias_-gender stereotyping — and its link with resume evaluation.

\section{Gender Stereotyping}

In addition to applicants' job-related resume information, there are other characteristics that, because of their saliency, may also affect how resume information is incorporated in selection decisionmaking. For example, Powell and Butterfield (2002) concluded that applicants' demographics explained additional variance in selection decisions beyond that already explained by applicants' qualifications. One of the most influential of these demographic characteristics is gender (Glick, Zion, \& Nelson, 1988; Pratto \& Bargh, 1991; Zikmund, Hitt, \& Pickens, 1978). Olian, Schwab, and Haberfeld (1988), for example, conducted a meta-analysis of experimental studies (1,842 participants across 19 studies) that examined gender effects on hiring recommendations. Their results indicated that the mean effect of applicant gender accounted for $4 \%$ of the variance in raters' hiring recommendations (Olian et al., 1988).

When applicant gender has been found to account for differences in selection decisions (Marlowe, Schneider, \& Nelson, 1996), gender stereotyping has been proposed as one explanation for those results (Biernat, 2003; Deaux, 1984; Fiske, Bersoff, Borgida, Deaux, \& Heilman, 1991). Gender stereotypes are usually referred to as generalizations held by a large proportion of the population that distinguish men from women and are stable over time (McCauley, Stitt, \& Segal, 1980). Specifically, men are commonly believed to exhibit "masculine" traits such as dominance, independence, and competitiveness, whereas women are believed to exhibit "feminine" traits such as dependence, nurturance, and communality (Martell, 1991). Although gender stereotypes have not been found to reflect actual sex differences, gender seems to influence individuals' beliefs and, more importantly, their expectations and evaluations of others (Deaux, 1984).

Two components (i.e., descriptive and prescriptive) of gender stereotyping have been identified (Eagly, 1987). The descriptive component consists of ideals regarding the characteristics possessed by a particular gender; however, the prescriptive component consists of beliefs about the characteristics that a gender should possess (Burgess \& Borgida, 1999).

Although gender may actually be relevant in a few jobs, in most cases it is irrelevant and only appears to be job-relevant when evaluators rely on stereotypes as they assess applicants' characteristics and their fit with job requirements (Heilman, 1983; Olian et al., 1988). In these instances, the descriptive gender-stereotyping component is operational. Numerous empirical studies have shown that applicants' gender and recruiters' stereotypes have strong effects on applicants' chances of being hired or promoted (Arvey, 1979; Glick et al., 1988; Marlowe et al., 1996; Olian et al., 1988; Pratto, Stallworth, Sidanius, \& Siers, 1997). For instance, research has shown that women are less likely to be hired than identically qualified men for managerial positions because evaluators perceived women to lack the behaviors and traits required for these jobs (Cejka \& Eagly, 1999). In addition, descriptive gender stereotyping was found to explain resume evaluators' more negative judgments of women's accomplishments as reported on their resumes than those accomplishments reported by men on their resumes (Olian et al., 1988).

By contrast, the prescriptive component of stereotyping involves recruiters' impressions of how one or the other gender is supposed to behave. That is, prescriptive stereotypes exist before applicants' resumes are screened, and when operational, such stereotypes might result in selection biases as well as discriminatory behavior by recruiters. For example, when women are perceived to have conducted themselves in a manner that is inconsistent with recruiters' prescriptive feminine stereotype, it is likely that those women will not be evaluated favorably. 
Indeed, Swim, Aiken, Hall, and Hunter (1995) found that men reported greater prejudice (e.g., traditional gender roles) and sexism beliefs (e.g., opinions about women's issues) than their women counterparts. Other studies have similarly demonstrated prescriptive stereotyping to be present in organizations (e.g., Burgess \& Borgida, 1999; Cota, Reid, \& Dion, 1991; Snizek \& Neil, 1992).

\section{The Present Study}

During resume evaluation, Keenan (1977), and later Ash et al. (1989), stressed the difficulty of identifying recruiters who have the ability to remain impartial during the screening process. Consequently, when recruiters evaluate applicants' resumes, it is likely that perceptual and memory processes, including confirmation biases and selective encoding and retrieval, operate to maintain stereotypical beliefs and prejudices (cf. Fiske \& Taylor, 1991). For example, Sande, Ellard, and Ross (1986) theorized that persons attempt to confirm the validity of their current perceptions of individuals by seeking out supportive information, in a biased manner, which affords confirmation. Similarly, after a series of studies of how individuals form and maintain stereotypes, Schaller (1992) concluded that even when data are interpreted in an unbiased manner and remembered flawlessly, membership in a particular group (e.g., gender) can still affect the formation and maintenance of group stereotypes.

In the present study, we examined simultaneously the relationship of applicant and recruiter gender on recruiters' perceptions of applicants' resume qualifications. Specifically, we focused on recruiters' assessments of three common categories of applicants' resume content: applicant work experience, extracurricular activities, and academic achievement. Whereas the job relatedness of applicants' work experience and academic achievements are evident, one might question how extracurricular activities reported on resumes is job relevant. In this regard, it has been shown, for example, that recruiters use extracurricular information as indicators of applicants' interpersonal skills, leadership ability, and motivation levels (Brown \& Campion, 1994). Furthermore, extracurricular activities have been reported to influence resume judges' attributions of perceived quality of applicants (Nemanick \& Clark, 2002), and they are associated with applicants' extraversion (Cole, Feild, \& Giles, 2003), a personality trait shown to predict job performance across a variety of sales and managerial types of positions.

To guide the formation of our research hypotheses, we framed them in the context of Eagly's (1987) gender role theory, which posits that sex differences in behavior are partially caused by the tendency of people to behave consistently within their gender roles. The masculine gender role, for example, is assumed to derive from men's historical role as family providers. In contrast, the traditional feminine gender role encompasses a distinctive communal component (e.g., social activities involving group membership, attention to interpersonal relationships, Rudman \& Glick, 1999). Consequently, stereotyping effects occur when individual members of a stereotyped group are judged as having more of some attribute than members of a comparison group (Biernat \& Kobrynowicz, 1997). Biernat (2003) has noted that because stereotyped attributes are readily diagnosed, the individuals stereotyped as possessing an attribute actually need less of it to document that they have the attribute. In cases when individuals' possess unexpected attributes (e.g., men who display high levels of nurturing behavior), judges require additional evidence to be certain that the persons actually possess the unexpected attribute.

To illustrate the possible role of applicant gender, consider an example where recruiters are presented with equivalent resumes from two applicants, Mike and Mary, and are asked for their perceptions of the applicants' work experiences. Under gender role theory, because of existing stereotypes, recruiters would be expected to judge Mike as having more work-related competencies than Mary has. Because of stereotyping, Mike would have to report fewer work experiences and abilities to meet minimum standards because recruiters will more readily discern the stereotyped attribute. Further, recruiters will require Mary's resume to report more work competencies than Mike's in order to meet minimum standards because they need additional evidence that ensures that Mary really does have appropriate work experience (i.e., unexpected attribute). In recruiters' minds, therefore, Mike needs less experience, Mary needs additional experience, and, as recruiters compare the two resumes, a contrast effect occurs in that Mike's resume is perceived as having more work experience than Mary's resume.

In regard to recruiter gender, we suggest that male and female recruiters differ in terms of their gender stereotypes. A number of studies have consistently shown gender differences with regard to 
stereotypes, particularly gender role beliefs (Snizek \& Neil, 1992; Twenge, 1997). Men have a greater tendency than women to endorse a more traditional feminine gender role (Pratto et al., 1997; Twenge, 1997). Snizek and Neil (1992) found that men were more likely than women to believe that women exhibit domestic qualities and lack "flair" for handling responsibility or authority. Accordingly, we predict that male recruiters will perceive female applicants' resumes as having more activities that pertain to the feminine gender role (e.g., social interests, group memberships, volunteering in community) than will female recruiters judging female applicants. In this same vein, we posit that female recruiters will judge male applicants' resumes as having more competencies related to the masculine gender role (e.g., work experiences) than will male recruiters judging male applicants.

In summary, Hypotheses 1 and 2 predict that recruiter gender will interact with applicant gender to predict recruiters' perceptions of information that applicants report on their resumes. These interactions are predicted because, based on the gender stereotyping literature, we believe that male recruiters will use a feminine stereotype, whereas female recruiters will employ a masculine stereotype, when they analyze resume content. Therefore, we hypothesize that:

Hypothesis 1: Recruiter gender will interact with applicant gender in such a way that female recruiters will judge male applicants as having more work experience than female applicants.

Hypothesis 2: Recruiter gender will interact with applicant gender in such a way that male recruiters will judge female applicants as having more $e x$ tracurricular activities than male applicants.

Given the absence of theory or past research to serve as a guide, a specific hypothesis concerning recruiters' perceptions of applicants' academic achievements was not formulated. Past research on applicant gender and academic qualifications has yielded mixed findings. For example, although women have been found to have higher academic achievement (Graves \& Powell, 1995), recruiters have judged both genders as having equal academic achievement (Dipboye et al., 1977). Further, we are unaware of any researchers who have investigated a possible interaction effect of recruiter and applicant gender on recruiters' judgments of applicants' academic qualifications. Therefore, in addition to our research hy- potheses, we explored the following research question: Does recruiter gender interact with applicant gender to influence recruiters' perceptions of applicants' academic achievements as reported on their resumes?

\section{METHOD}

\section{Participants}

\section{Job Applicant Sample}

Three upper-division management classes were recruited to participate in the study. We asked the students to submit a current resume to the principal investigator. Of the 217 students invited to participate, $99(46 \%)$ submitted usable resumes. The majority $(89 \%)$ of the participants were graduating seniors. Men reported an average age of 22.7 years $(S D=2.3)$, and women reported an average age of 22.6 years $(S D=2.2)$. Approximately one half $(48.5 \%)$ were men; $87 \%$ were White.

\section{Recruiter Sample}

Experienced resume reviewers were contacted from an employer list maintained by the College of Business at the university where the study was conducted. Each contacted employer had previously hired business students from Auburn University's College of Business.

Of the 40 resume reviewers who volunteered and received research packets, only two withdrew from the study. We replaced them with two other recruiters solicited from the employer contact list. The judges were human resource recruiters or managers involved in recruiting, and they came from 35 organizations that represent a wide variety of industries including manufacturing, retail, telecommunications, technology, and professional services. The recruiters averaged 35 years of age $(S D=8.0)$, all were college graduates, $35 \%$ reported graduate work; $53 \%$ were women, and $93 \%$ were White. Two thirds of the recruiters $(68 \%)$ indicated they spent at least $25 \%$ or more of their time reviewing job applicants' resumes.

\section{Resume Rating Instrument}

We employed a slightly modified version of Brown and Campion's (1994) resume rating form. Based on their review of the literature as well as 249 
employment resumes, Brown and Campion (1994) identified 22 items common to resumes and typically encountered by recruiters. We omitted four of these items from our resume rating form. Two items ("dorm advisor" and "recreational sports participant") were eliminated because applicants in our study did not report them. Two additional items had excessive overlap, that is, "individual job achievement" and "work awards." Therefore, of these two items, we eliminated the one judged by Brown and Campion's recruiters to have the lowest mean reported use, that is, "work awards." Finally, the item "job-related degree" was excluded because all applicants' resumes reported a bachelor's degree in business.

\section{Procedure}

Recruiters who agreed to participate in the study were sent a short introduction to thank them for their participation, directions on how to complete enclosed materials, resume scoring forms, and 10 randomly assigned applicant resumes. At no point were the resume reviewers aware the of the study's hypotheses. Finally, the resumes were assigned so that each of the 99 resumes was rated by four recruiters; this resulted in 388 evaluations.

For 16 of the 18 resume items, the reviewers rated the extent to which each topic appeared on each applicant's resume. Judgments of the extent to which a topic was present on a resume were made using a slightly modified version of Brown and Campion's (1994) 5 -point rating scale $(1=$ None; 5 $=$ Considerable amount). Rather than using "None" as the descriptor of the lowest rating scale point, we substituted the words "Did Not Mention" as it was possible that applicants could have possessed some amount of a resume item but simply omitted it from their resume. In order to make the two GPA variables (overall GPA and GPA in major) consistent with the 5-point rating scale used with the other 16 resume items, GPA was coded as 1 if the student did not mention it on the resume. This procedure reflected previous research that indicates that, when applicants choose to omit GPA information, their GPA is assumed to be low (Stone \& Stone, 1987; Thoms, McMasters, Roberts, \& Dombkowski, 1999). Next, listed GPAs were divided into quartiles; the lowest quartile was assigned a value of 2 , the next highest was equal to 3 , the next highest equal to 4 , and the highest quartile was equal to 5 .

\section{Data Analyses}

In order to develop composite criterion variables, principal components analysis using varimax rotation was conducted on the 18 resume items. To determine the number of appropriate factors, we considered the eigenvalue-greater-than- 1 rule, the scree test, and factor loadings greater than .40 (Fabrigar, Wegener, MacCallum, \& Strahan, 1999; Nunnally, 1978). The results revealed three factors (which explained $52 \%$ of the variance) that generally reflected Brown and Campion's (1994) original resume categories. The first factor was labeled work experience $($ alpha $=.74)$. It was composed of three resume items (full-time work experience, supervised others, and worked during college). The second factor, labeled extracurricular activities, consisted of five items $($ alpha $=.74)$ : membership in a social fraternity or sorority, elected offices held, membership in college clubs, volunteered for community activities, and computer experience (negatively loaded). It was interesting that computer experience negatively loaded on the extracurricular activities factor. However, we believe that there is a reasonable explanation for this finding. In an earlier study (Cole et al., 2003), we found that applicants' extracurricular activities were positively related to their extraversion levels. That is, extraverted applicants were more likely to be involved in social clubs, etc., whereas introverted applicants were less likely to get involved in such activities. Accordingly, we suspect that introverted persons are more likely to enjoy activities, and careers (e.g., computer programming), that do not require social interaction. Consequently, an activity such as computer experience might be expected to exhibit a negative loading on the extracurricular activities factor. Academic achievement, factor three, was composed of five resume items (alpha $=.78)$. They included Dean's list, overall GPA, scholastic awards, professional associations, and GPA in major. The five remaining resume items either did not load $(<.40)$ on one of three factors or exhibited cross-loadings greater than .20. To develop scales for the three factors derived from the factor analysis, resume item ratings that loaded on a specific factor were averaged. These three resume composites served as criterion variables in testing our hypotheses and research question. Intraclass correlations for the four recruiters rating the same resume on the three factors of work experience, extracurricular activities, and academic achievement ranged from .64 to .97 . 
Because the processes used by individual resume evaluators may be unstandardized and idiosyncratic (Ash et al., 1989), there was a potential for extreme judgments to exert unduly amounts of influence on statistical tests. Therefore, we assessed outlier influence using DFFITS (Neter, Kutner, Nachtsheim, \& Wasserman, 1996) and Cook's distance measure (Neter et al., 1996). Based on the evaluation of these measures, eight cases were identified as having unacceptable effects on the analyses. Statistical tests indicated that the eight cases were significantly different from the other remaining recruiters' judgments; the outlying recruiters' judgments were significantly higher. As a result, these eight cases were eliminated from all subsequent analyses.

Because age and race have been shown to bias recruiter perceptions (e.g., Graves \& Powell, 1995), they were used as covariates in study analyses. First, a multiple analysis of covariance (MANCOVA) was conducted on the three criteria (work experience, extracurricular activities, and academic achievement), using applicant and recruiter gender as the independent variables and controlling for applicants' age and race. Next, follow-up analyses of covariance (ANCOVA) were performed for each of the three criteria.

\section{RESULTS}

Table I reports the means, standard deviations, and intercorrelations for the study variables. Academic achievements and extracurricular activities were positively correlated, $r=.42, p<.01$. Applicant gender showed a negative association with work experience, $r=-.20, p<.01$, and positive correlations with academic achievements, $r=.15, p<.01$, and extracurricular activities, $r=.17, p<.01$. More specifically, male applicants were perceived to have more work experience, and female applicants were perceived to have more extracurricular activities and academic achievements.

\section{Hypotheses Testing}

An overall applicant gender $\times$ recruiter gender interaction effect was found for the MANCOVA, $F(3,368)=4.78, p<.01$, and follow-up analyses of covariance (ANCOVA) were performed for each of the three criteria (see Table II). Two analyses are presented in the table: one without the eight outlier cases and one with them. The results were similar for both.

Hypothesis 1 stated that female recruiters would rate male applicants to have more work experience than female applicants; we anticipated no gender differences in work experience ratings given by male recruiters. As predicted, Table II shows that the interaction was significant for work experience, $F(1,370)=5.71, p=.017$. Figure 1 shows a plot of the interaction for the work experience ratings. Male recruiters rated male applicants as having only slightly more work experiences $(M=2.60)$ than female applicants $(M=2.45)$; this difference was not significant $(p>.05)$. However, female recruiters rated male applicants' resumes to report significantly $(p<.05)$ more work experiences $(M=2.97)$ than those of female applicants $(M=2.34)$. Thus, Hypothesis 1 was supported.

With regard to Hypothesis 2, we expected that male recruiters would rate female applicants as having more extracurricular activities than male applicants; no applicant gender differences were expected for female recruiters. As hypothesized and shown in Table II, the interaction was significant for extracurricular activities, $F(1,370)=5.53, p=.019$. As illustrated in Fig. 2, male recruiters rated female applicants as having more $(p<.05)$ extracurricular interests $(M=2.41)$ than male applicants $(M=$ 1.95). Female recruiters rated both male $(M=2.16)$

Table I. Means, Standard Deviations, and Intercorrelation Matrix of Study Variables

\begin{tabular}{lccrrrrr}
\hline \multicolumn{1}{c}{ Variable } & $M$ & $S D$ & 1 & 2 & 3 & 4 & 5 \\
\hline 1. Applicant gender $^{a}$ & 0.52 & 0.50 & - & & & & \\
2. Recruiter gender & & & \\
3. Academic achievements & 0.53 & 0.50 & -.01 & - & & & \\
4. Work experience & 2.01 & 0.96 & .15 & .00 & $(.78)$ & & \\
5. Extracurricular activities & 2.59 & 1.00 & -.20 & .07 & -.01 & $(.74)$ & \\
\hline
\end{tabular}

Note. $N=388$. Correlations greater than .14 are significant at $p<.01$. Coefficient alphas are reported on the diagonal. All tests are two-tailed.

${ }^{a}$ Applicant and recruiter gender coded as $0=\operatorname{man} ; 1=$ woman. 
Table II. Analysis of Covariance for Recruiters' Judgments of Applicants' Work Experience, Extracurricular Activities, and Academic Achievements

\begin{tabular}{|c|c|c|c|c|c|c|c|}
\hline \multirow[b]{2}{*}{ Source } & \multirow[b]{2}{*}{$d f$} & \multicolumn{2}{|c|}{ Work experience } & \multicolumn{2}{|c|}{ Extracurricular activities } & \multicolumn{2}{|c|}{ Academic achievements } \\
\hline & & $F$ & $\eta^{2}$ & $F$ & $\eta^{2}$ & $F$ & $\eta^{2}$ \\
\hline \multicolumn{8}{|c|}{ Corrected data that excludes extreme outliers } \\
\hline \multicolumn{8}{|c|}{ Covariates $^{a}$} \\
\hline Age & 1 & .39 & .001 & .17 & .000 & .27 & .001 \\
\hline Race & 1 & .99 & .003 & $6.76^{* *}$ & .018 & 1.70 & .005 \\
\hline Applicant gender $(\mathrm{A})^{b}$ & 1 & $14.88^{* *}$ & .039 & $10.79^{* *}$ & .028 & $8.39^{* *}$ & .022 \\
\hline Recruiter gender $(\mathrm{R})^{b}$ & 1 & 1.78 & .005 & .07 & .000 & .01 & .000 \\
\hline $\mathrm{A} \times \mathrm{R}$ & 1 & $5.71^{*}$ & .015 & $5.53^{*}$ & .015 & .17 & .000 \\
\hline Residual & 370 & & & & & & \\
\hline \multicolumn{8}{|c|}{ Uncorrected data that includes extreme outliers } \\
\hline \multicolumn{8}{|c|}{ Covariates $^{a}$} \\
\hline Age & 1 & .28 & .001 & .10 & .000 & .15 & .000 \\
\hline Race & 1 & .92 & .002 & $7.92^{* *}$ & .021 & 2.22 & .006 \\
\hline Applicant gender $(\mathrm{A})^{b}$ & 1 & $15.09^{* *}$ & .038 & $11.02^{* *}$ & .028 & $10.05^{* *}$ & .026 \\
\hline Recruiter gender $(\mathrm{R})^{b}$ & 1 & 1.88 & .005 & .09 & .000 & .10 & .000 \\
\hline $\mathrm{A} \times \mathrm{R}$ & 1 & $4.56^{*}$ & .012 & $3.58^{\dagger}$ & .009 & .14 & .000 \\
\hline Residual & 378 & & & & & & \\
\hline
\end{tabular}

Note. Eight recruiters judged to be outliers were removed from the corrected data analysis. In the uncorrected data analysis, these eight recruiters were included.

${ }^{a}$ Applicant's age coded in years and race coded as $1=$ Person of Color; $2=$ White.

${ }^{b}$ Applicant and recruiter gender coded as $0=\operatorname{man} ; 1=$ woman.

$\dagger<.10$ (two-tailed). ${ }^{*} p<.05$ (two-tailed). ${ }^{* *} p<.01$ (two-tailed).

and female $(M=2.24)$ applicants as having about the same $(p>.05)$ amount of extracurricular activity information on their resumes. These results supported Hypothesis 2.
With regard to our research question, we were interested in examining the possible influence of a recruiter gender $\times$ applicant gender interaction on recruiters' ratings of applicants' academic

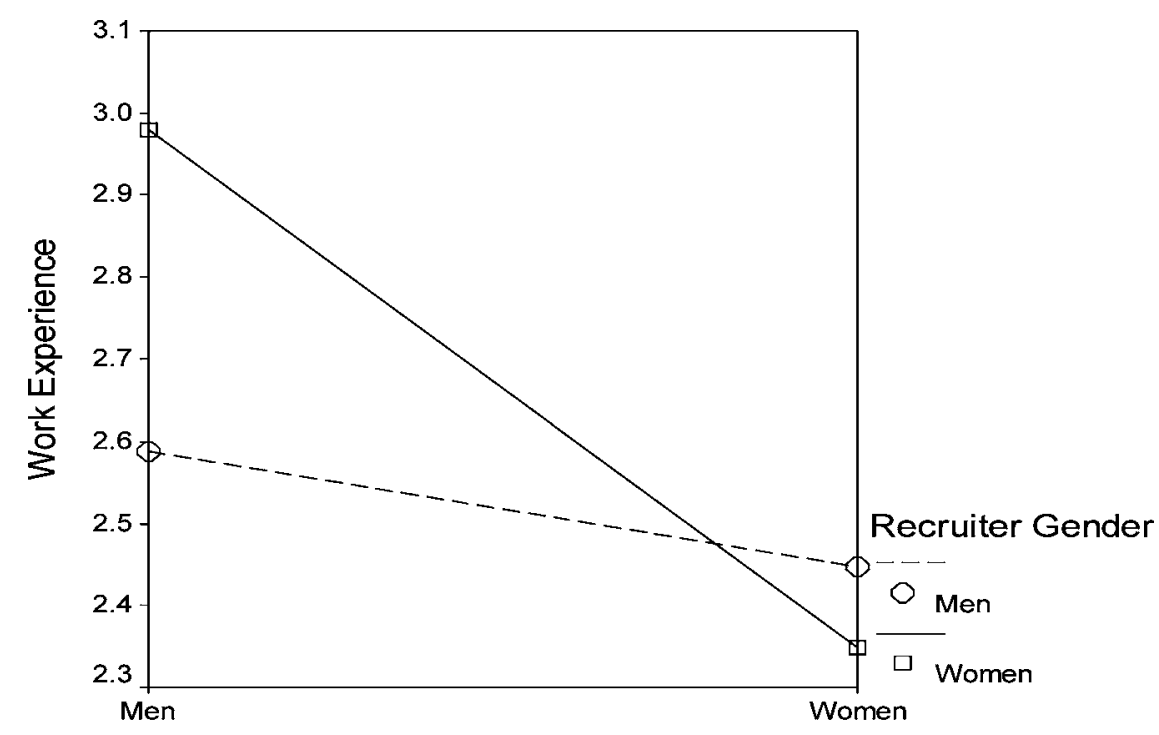

Applicant Gender

Fig. 1. Effect of applicant gender $\times$ recruiter gender interaction on recruiters' ratings of applicant work experience. 


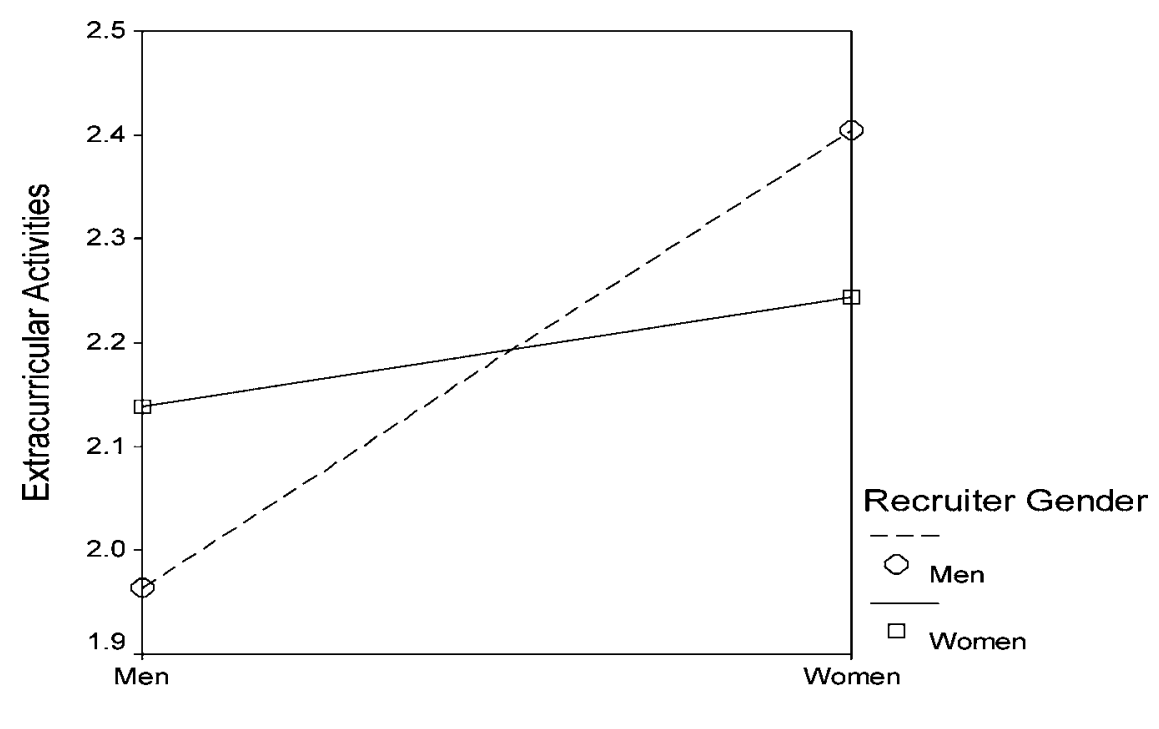

Applicant Gender

Fig. 2. Effect of applicant gender $\times$ recruiter gender interaction on recruiters' ratings of applicant extracurricular activities.

achievements. The nonsignificant interaction, $F(1,370)=.17, \quad p=n s$, showed that recruiter gender did not interact with applicant gender to influence recruiters' ratings of applicants' academic achievements.

\section{DISCUSSION}

Our general proposition that recruiters' and applicants' gender will influence recruiters' judgments regarding applicants' resume qualifications was supported. Because recruiters typically act as employers' gatekeepers by providing initial applicant screening decisions, our results suggested gender biases during organizational recruitment and selection may be occurring. For example, for the type of applicant population used in the present study (soon-to-be college graduates), there are typically many applicants for a much smaller number of entry-level positions. Given this situation, our findings suggest that women applying for jobs that require "masculine" qualifications (e.g., supervision of others, full-time work experience) and men applying for jobs that require "feminine" qualifications (e.g., nurturing, communal involvement) may be stereotypically judged as a poor fit by recruiters (cf. Heilman, 1983).

As opposed to typical resume review situations, gender biases may be more evident and therefore more likely to be addressed in a face-to-face in- terview context. In contrast, gender biases that occur during resume evaluation are more likely to be nonconscious and difficult to detect. This contention is consistent with the distinction between the controlled and automatic attentional processes of attribution theory (Feldman, 1982). Persons may employ either a controlled or an automatic process when evaluating information; the context of the information is the determinant of which process is employed. When judges are given relatively large amounts of information, a controlled process characterized by an awareness of salient information and conscious control occurs (Arvey, 1979; Tosi \& Einbender, 1985). Within an interview context, then, when given reasonably large amounts of applicant information (e.g., resume and application, test scores, applicant behavior and responses during an interview), recruiters are more likely consciously to evaluate and categorize applicants (i.e., qualified, not qualified) based on jobrelevant qualifications including education, experience, and behaviors (Heilman, 1984).

The automatic process, in contrast, occurs without awareness and may be induced by focusing on information associated with certain people and their attributes (Feldman, 1982). For example, when recruiters screen applicants' resumes, they are limited to information reported by the applicant. In such instances, it may be that recruiters infer the attribute of gender through an applicant's name and, with varying degrees of disregard of applicants' job-relevant 
information, may inaccurately evaluate applicants. For example, a female applicant may be stereotyped into a feminine category, and as such, be judged (accurately or inaccurately) as not having the same qualifications and experience as a male applicant. The results of Tosi and Einbender's (1985) meta-analysis support this explanation. They found that judges faced with making evaluations and having limited applicant information regarding qualifications or job requirements were inclined to make biased or stereotyped judgments, whereas judges with more information did not exhibit such bias. Similarly, Oliphant and Alexander (1982) noted that resume raters reacted in biased and unpredictable ways to candidates who reported incomplete resume information.

Our study has limitations that need to be addressed. First, an anonymous reviewer raised the possibility that the resumes in our study may have undergone more scrutiny than would have occurred in an actual selection context. In other words, could our results have been influenced by the fact that recruiters were asked to make judgments regarding 18 specific resume items as opposed to evaluating "whole" resumes? With regard to selection interviews, standardization and additional structure have been shown to increase interview validity dramatically (Schmidt \& Hunter, 1998). Likewise, the incorporation of additional structure in the resume evaluation process might increase recruiters' ability to judge applicants' resume information reliably and accurately as well as to decrease rating biases (see, for example, structured rating procedures employed by Pulakos, Schmitt, Whitney, \& Smith, 1996). In fact, the use of a standardized rating format may have helped to minimize recruiter rating errors. Therefore, our results may have been even stronger if entire resumes were screened with less structure in the evaluation process. Furthermore, Tourangeau and Rasinski (1988) argued that a study's contextual effects are less likely to create bias when participants are experienced in making similar evaluations. As we noted earlier, all judges were experienced recruiters employed by organizations that had recently hired job applicants from the same college of business attended by the applicants in the current study.

Second, caution should be exercised when considering our suggestion that gender stereotypes may bias recruiters' judgments during resume evaluation. For example, although female recruiters perceived male applicants to have more work experience than did male recruiters, we are unable to determine whether male applicants in our sample actually pos- sessed more work experiences, or whether female recruiters mistakenly perceived them to have more experiences. Similar concerns exist for male recruiters and female applicants. Consequently, it is not possible to determine which group of raters, men or women, were more accurate in rating applicants on each of the three criteria. Although naturalistic studies such as ours enhance external validity, they typically do not have the controls associated with laboratory experiments. In future studies, researchers might consider using the same resumes but changing the gender to the contrary as well as to something gender neutral.

A third limitation involves the modest amount of incremental variance explained by the interaction terms. However, researchers have noted that moderator effects that explain even small amounts of variance can be important (Evans, 1985). Furthermore, indices of variance accounted for may be misleading when small influences sum to produce a meaningful outcome (Abelson, 1985), especially if the bias results in equal employment opportunity litigation. For example, in a computer simulation, Martell, Lane, and Emrich (1996) demonstrated the robust effect of very small amounts of gender bias. Although gender bias accounted for only $1 \%$ of the variance in decision to hire, after eight rounds of competition for "promotion" to the next hierarchical level, men $(65 \%)$ outnumbered women $(35 \%)$ at the highest level of management.

A final note of caution is that we did not ask recruiters for their overall ratings of applicants' employability for a specific job position. Thus, we were unable to determine if the gender biases found in the current study affected recruiters' employability judgments. The omission of this latter variable, however, was intentional as we were concerned that recruiters' employability judgments might contaminate their assessments of resume information. For example, it has been shown in performance appraisal research that managers often assign overall performance ratings to employees before assigning specific performance dimension ratings, and then "adjust" the individual dimension ratings to arrive at the same conclusion as the overall ratings (Longenecker, Sims, \& Gioia, 1987). In addition, previous studies have confirmed the effect of applicant gender on recruiters' evaluations for numerous job positions (see Powell's, 1987 review). What the results of the present study do indicate is that gender bias can occur at the initial point of contact (i.e., the resume screening process) between applicants and recruiters. 
In addition to its limitations, our study possesses strengths as well. We used experienced human resource recruiters who were assigned actual applicants' resumes and asked to evaluate their job qualifications. Thus, the naturalistic context of the study is similar to actual, preemployment personnel decisionmaking in the "real world," that is, recruiters evaluating applicants' resumes without having seen the applicants. Moreover, in earlier research, Marlowe et al. (1996) found that inexperienced managers were more likely to exhibit the most pronounced gender biases. Our use of highly experienced recruiters who regularly make hiring and promotion decisions may have led to a conservative estimate of the extent to which gender biases may be occurring in resume evaluation.

With regard to future research, two directions appear promising. First, research is needed to investigate other recruiter characteristics that may be associated with recruiters' inclination to allow gender stereotypes to influence their evaluations. Some possible recruiter characteristics that could be studied are beliefs concerning the ideal applicant, implicit personality theories (Idson \& Mischel, 2001), levels of training and experience, and support provided by the organization. Second, future researchers should examine the impact of incorporating structure and standardized methods in resume assessment. Procedures similar to structured interviewing (such as incorporating standardized rating scales for assessing resume content) could be used to reduce recruiter errors and therefore increase the reliability and validity of recruiters' evaluations of applicants' resumes.

\section{CONCLUSION}

Resume screening is the starting point of many hiring decisions. Despite its outward appearance as a straightforward process, organizations should not necessarily assume their recruiters make reliable and valid assessments of applicants' resume qualifications. In the current study, male and female recruiters differed in their ratings of the presence of job experience and extracurricular activity information on the resumes of male and female applicants. These findings are congruent with personality research that has demonstrated that gender-typed individuals wish to preserve gender norms and are prejudiced against those who violate these gender norms (Frable, 1989). Thus, organizations may wish to take into account the gender of recruiters and applicants before re- sume screening is undertaken. Furthermore, we support Brown and Campion's (1994) suggestion that resume evaluators should always be trained, and, whenever possible, that the resume evaluation process be standardized.

It has been suggested that gender stereotypes will slowly disappear as more and more women enter the workforce. Nonetheless, as researchers have shown, many "old fashioned" attitudes persist in individuals (Glick \& Fiske, 1997; Swim et al., 1995). Accordingly, the current findings suggest gender stereotypes still exist in organizations. Thus, how does the entry of women into the workforce change perceptions of male and female roles in society? What does this all mean for gender stereotypes in 50 years? As societies continue to change, will stereotypes still exist, will they reverse, or will they become even more solidified? Only future research can begin to address such questions.

\section{ACKNOWLEDGMENTS}

The authors thank the editor and two anonymous reviewers for their valuable comments and suggestions.

\section{REFERENCES}

Abelson, R. P. (1985). A variance explanation paradox: When a little is a lot. Psychological Bulletin, 97, 129-133.

Arvey, R. (1979). Unfair discrimination in the employment interview: Legal and psychological aspects. Psychological Bulletin, 86, 736-765.

Ash, R. A., Johnson, J. C., Levine, E. L., \& McDaniel, M. A. (1989). Job applicant training and work experience evaluation in personnel selection. Research in Personnel and Human Resources Management, 7, 183-226.

Biernat, M. (2003). Toward a broader view of social stereotyping. American Psychologist, 58, 1019-1027.

Biernat, M., \& Kobrynowicz, D. (1997). Gender- and race based standards of competence: Lower minimum standards but higher ability standards for devalued groups. Journal of Personality and Social Psychology, 72, 544-557.

Bretz, R. D., Rynes, S. L., \& Gerhart, B. (1993). Recruiter perceptions of applicant fit: Implications for individual career preparation and job search behavior. Journal of Vocational Behavior, 43, 310-327.

Brown, B. K., \& Campion, M. A. (1994). Biodata phenomenology: Recruiters' perceptions and use of biographical information in resume screening. Journal of Applied Psychology, 79, 897908.

Burgess, D., \& Borgida, E. (1999). Who women are, who women should be: Descriptive and prescriptive gender stereotyping in sex discrimination. Psychology, Public Policy, \& Law, 5, 665-692.

Cable, D. M., \& Gilovich, T. (1998). Looked over or overlooked? Prescreening decisions and postinterview evaluations. Journal of Applied Psychology, 83, 501-508. 
Cejka, M. A., \& Eagly, A. H. (1999). Gender-stereotypic images of occupations correspond to the sex segregation of employment. Personality and Social Psychology Bulletin, 25, 413-423.

Cohen, S. L., \& Bunker, K. A. (1975). Subtle effects on sex role stereotypes on recruiters' hiring decisions. Journal of Applied Psychology, 60, 566-572.

Cole, M. S., Feild, H. S., \& Giles, W. F. (2003). Using recruiter assessments of the presence of resume information to predict applicant mental ability and Big Five personality dimensions. International Journal of Selection and Assessment, 11, 78-88.

Cota, A. A., Reid, A., \& Dion, K. L. (1991). Construct validity of a diagnostic ratio measure of gender stereotypes. Sex Roles, 25, 225-235.

Deaux, K. (1984). From individual differences to social categories: Analysis of a decade's research on gender. American Psychologist, 39, 105-116.

Dipboye, R. L., Arvey, R. D., \& Terpstra, D. E. (1977). Sex and physical attractiveness of raters and applicants as determinants of resume evaluations. Journal of Applied Psychology, 62, 288-294

Dipboye, R. L., Fontenelle, G. A., \& Garner, K. (1984). Effects of previewing the application on interview process and outcomes. Journal of Applied Psychology, 69, 118-128.

Dipboye, R. L., Fromkin, H. L., \& Wiback, K. (1975). Relative importance of applicant sex, attractiveness and scholastic standing in evaluation of job applicant resumes. Journal of Applied Psychology, 60, 39-43.

Dougherty, T. W., Turban, B. B., \& Callender, J. C. (1994). Confirming first impressions in the employment interview: A field study of interviewer behavior. Journal of Applied Psychology, $79,659-665$.

Eagly, A. H. (1987). Sex differences in social behavior: A socialrole interpretation. Hillsdale, $\mathrm{NJ}$ : Erlbaum.

Evans, M. G. (1985). A Monte Carlo study of the effects of correlated method variance in moderated multiple regression analysis. Organizational Behaviors and Human Decision Processes, 36, 305-323.

Fabrigar, L. R., Wegener, D. T., MacCallum, R. C., \& Strahan, E. J. (1999). Evaluating the use of exploratory factor analysis in psychological research. Psychological Methods, 4, 272-299.

Feldman, J. M. (1982). Perception cognition and performance. In H. Tosi \& W. Hamner (Eds.), Organizational behavior and management: A contingency approach (pp. 157-174). New York: Wiley \& Sons.

Fiske, S. T., Bersoff, D. N., Borgida, E., Deaux, K., \& Heilman, M. E. (1991). Social science research on trial: Use of sex stereotyping research in Price Waterhouse v. Hopkins. American Psychologist, 46, 1049-1060.

Fiske, S. T., \& Taylor, S. E. (1991). Social Cognition (2nd ed.). New York: McGraw-Hill.

Frable, D. E. S. (1989). Sex typing and gender ideology: Two facets of the individual's gender psychology that go together. Journal of Personality and Social Psychology, 56, 95-108.

Gatewood, R. D., \& Feild, H. S. (2001). Human resource selection (5th ed.). Fort Worth, TX: Harcourt.

Glick, P., \& Fiske, S. T. (1997). Hostile and benevolent sexism: Measuring ambivalent sexist attitudes toward women. Psychology of Women Quarterly, 21, 119-138.

Glick, P., Zion, C., \& Nelson, C. (1988). What mediates sex discrimination in hiring decisions? Journal of Personality and Social Psychology, 55, 178-186.

Graves, L. M. (1993). Sources of individual differences in interviewer effectiveness: A model and implications for future research. Journal of Organizational Behavior, 14, 349-370.

Graves, L. M., \& Powell, G. N. (1995). The effect of sex similarity on recruiters' evaluations of actual applicants: A test of the similarity-attraction paradigm. Personnel Psychology, 48, 8598.
Hakel, M. D., \& Schuh, A. J. (1971). Job applicant attributes judged important across seven diverse occupations. Personnel Psychology, 24, 45-52.

Heilman, M. E. (1983). Sex bias in work settings: The lack of fit model. Research in Organizational Behavior, 5, 269-298.

Heilman, M. E. (1984). Information as a deterrent against sex discrimination: The effects of applicant sex and information type on preliminary employment decisions. Organizational Behavior and Human Performance, 23, 360-372.

Hutchinson, H. L. (1984). Personnel administrators' preferences for resume content. Journal of Business Communication, 21, $5-14$.

Idson, L. C., \& Mischel, W. (2001). The personality of familiar and significant people: The lay perceiver as a social-cognitive theorist. Journal of Personality and Social Psychology, 80, 585596.

Keenan, A. (1977). Some relationships between interviewers' personal feelings about candidates and their general evaluation of them. Journal of Occupational Psychology, 50, 275283.

Kinicki, A. J., Lockwood, C. A., Hom, P. W., \& Griffeth, R. W. (1990). Interviewer predictions of applicant qualifications and interviewer validity: Aggregate and individual analyses. Journal of Applied Psychology, 75, 477-486.

Knouse, S. B. (1989). The role of attribution theory in personnel employment selection: A review of the recent literature. Journal of General Psychology, 116, 183-196.

Levine, E. L., \& Flory, A. (1975). Evaluation of job applicationsA conceptual framework. Public Personnel Management, 4, 378-385.

Lievens, F., van Dam, K., \& Anderson, N. (2002). Recent trends and challenges in personnel selection. Personnel Review, 31, $580-601$.

Longenecker, C. O., Sims, H. P., \& Gioia, D. A. (1987). Behind the mask: The politics of employee appraisal. Academy of Management Executive, 1, 183-193.

Marlowe, C. M., Schneider, S. L., \& Nelson, C. E. (1996). Gender and attractiveness biases in hiring decisions: Are more experienced managers less biased? Journal of Applied Psychology, $81,11-21$.

Martell, R. (1991). Sex bias at work: The effects of attentional and memory demands on performance ratings of men and women. Journal of Applied Social Psychology, 21, 1939-1960.

Martell, R. F., Lane, D. M., \& Emrich, C. (1996). Male-female differences: A computer simulation. American Psychologist, $51,157-158$

McCauley, C., Stitt, C. L., \& Segal, M. (1980). Stereotyping : From prejudice to prediction. Psychological Bulletin, 87, 195-208.

Mohamed, A. A., Orife, J. N., \& Wibowo, K. (2002). The legality of keyword search as a personnel selection tool. Employee Relations, 24, 516-522.

Nemanick, R. C., \& Clark, E. M. (2002). The differential effects of extracurricular activities on attributions in resume evaluation. International Journal of Selection and Assessment, 10, 206-217.

Neter, J., Kutner, M. H., Nachtsheim, C. J., \& Wasserman, W. (1996). Applied linear statistical models. New York: McGraw-Hill.

Nunnally, J. C. (1978). Psychometric theory (2nd ed.). New York: McGraw-Hill.

Olian, J. D., Schwab, D. P., \& Haberfeld, Y. (1988). The impact of applicant gender compared to qualifications on hiring recommendations: A meta-analysis of experimental studies. Organizational Behavior and Human Decision Processes, 41, 180195.

Oliphant, V. N., \& Alexander, E. R., III. (1982). Reactions to resumes as a function of resume determinateness, applicant characteristics, and sex of raters. Personnel Psychology, 35, 829-842. 
Powell, G. N. (1987). The effects of sex and gender on recruitment. Academy of Management Review, 12, 731-743.

Powell, G. N., \& Butterfield, D. A. (2002). Exploring the influence of decision makers' race and gender on actual promotions to top management. Personnel Psychology, 55, 397-427.

Pratto, F., \& Bargh, J. A. (1991). Stereotyping based on apparently individuating information: Trait and global components of sex stereotypes under attention overload. Journal of Experimental Social Psychology, 27, 26-47.

Pratto, F., Stallworth, L. M., Sidanius, J., \& Siers, B. (1997). The gender gap in occupational role attainment: A social dominance approach. Journal of Personality and Social Psychology, $72,37-53$.

Pulakos, E. D., Schmitt, N., Whitney, D., \& Smith, M. (1996). Individual differences in interviewer ratings: The impact of standardization, consensus discussion, and sampling error on the validity of a structured interview. Personnel Psychology, 49, $85-102$.

Rudman, L. A., \& Glick, P. (1999). Feminized management and backlash toward agentic women: The hidden costs to women of a kinder, gentler image of middle managers. Journal of Personality and Social Psychology, 77, 1004-1010.

Sande, G. N., Ellard, J. H., \& Ross, M. (1986). Effect of arbitrarily assigned status labels on self-perceptions and social perceptions: The mere position effect. Journal of Personality and Social Psychology, 50, 684-689.

Schaller, M. (1992). In-group favoritism and statistical reasoning in social inference implications for formation and maintenance of group stereotypes. Journal of Personality and Social Psychology, 63, 61-74.

Schmidt, F. L., \& Hunter, J. E. (1998). The validity and utility of selection methods in personnel psychology: Practical and theoretical implications of 85 years of research findings. Psychological Bulletin, 124, 262-274.

Snizek, W. E., \& Neil, C. C. (1992). Job characteristics, gender stereotypes, and perceived gender discrimination in the workplace. Organizational Studies, 13, 403-427.

Stone, D. L., \& Stone, E. F. (1987). Effects of missing applicationblank information on personnel selection decisions: Do privacy protection strategies bias the outcome? Journal of Applied Psychology, 72, 452-456.

Swim, J. K., Aiken, K. J., Hall, W. S., \& Hunter, B. A. (1995). Sexism and racism: Old-fashioned and modern prejudices. Journal of Personality and Social Psychology, 68, 199-214.

Thoms, P., McMasters, R., Roberts, M. R., \& Dombkowski, D. A. (1999). Resume characteristics as predictors of an invitation to interview.Journal of Business and Psychology, 13, 339356.

Tosi, H. L., \& Einbender, S. W. (1985). The effects of the type and amount of information in sex discrimination research: A meta-analysis. Academy of Management Journal, 28, 712723.

Tourangeau, R., \& Rasinski, K. A. (1988). Cognitive processes underlying context effects in attitude measurement. Psychological Bulletin, 103, 299-314.

Twenge, J. M. (1997). Attitudes toward women, 1970-1995: A meta-analysis. Psychology of Women Quarterly, 21, 35-51.

Useem, J. (1999, July 5). For sale online: You. Fortune, pp. 67-78.

Zedeck, S., Tziner, A., \& Middlestadt, S. E. (1983). Interviewer validity and reliability: An individual analysis approach. Personnel Psychology, 36, 355-370.

Zikmund, W. G., Hitt, M. A., \& Pickens, B. A. (1978). Influence of sex and scholastic performance on reactions to job applicant resumes. Journal of Applied Psychology, 63, 252-254. 